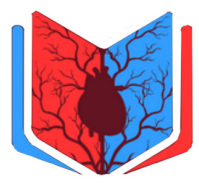

Published By : IVAA

the Indonesian Vascular Access Association

\title{
A three years' experience of Arteriovenous Fistula (AVF) cases in a tertiary care hospital of East Java, Indonesia: a descriptive observational study
}

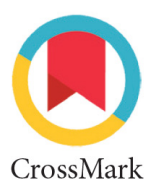

\author{
Rafaela Andira Ledyastatin ${ }^{1 *}$, Caesario Tri Prasetyo ${ }^{1}$, \\ Gold Sunday Palm Tampubolon', Dhihintia Jiwangga²
}

'Resident of Thoracic-Cardiac and Vascular Surgery, Faculty of Medicine, Universitas Airlangga, Dr. Soetomo Academic General Hospital, Surabaya, Indonesia

${ }^{2}$ Senior Consultant, Department of Thoracic-Cardiac and Vascular Surgery, Faculty of Medicine, Universitas Airlangga, Dr. Soetomo Academic General Hospital, Surabaya, Indonesia
*Corresponding to: Rafaela Andira Ledyastatin; Resident of Thoracic-Cardiac and Vascular Surgery, Faculty of Medicine, Universitas Airlangga, Dr. Soetomo Academic General Hospital, Surabaya, Indonesia; rafaela.andira@yahoo.com

Received: 2021-04-26 Accepted: 2021-10-15 Published: 2021-12-17

\section{ABSTRACT}

Introduction: The incidence of end-stage renal disease (ESRD) globally is 700 million people approximately. Patients with ESRD need vascular access for hemodialysis as renal replacement therapy (RRT). Among hemodialysis access, arteriovenous fistula is considered as the most preferred form of vascular access due to its characteristics. This study aimed to to present a descriptive characteristic of arteriovenous fistula creation cases in a tertiary care hospital with a specific view of demographic parameters, fistulas' sites, type of fistulas.

Methods: We conducted a descriptive study of single-center in the Department of Thoracic, Cardiac and Vascular Surgery of Dr. Soetomo Academic General Hospital Surabaya, collected data from January 1st, 2017 to December 31st, 2020. All patients who undergo arteriovenous fistula creation considered as a subject in this study. We retrieved the characteristics of the patients, the type of fistula, the site, surgical technique, and underlying disease from patients' electronic medical data records. Results: A total of 167 patients requiring long-term hemodialysis in our center. Females were dominantly in our study with $56.9 \%$ (95). Most of AVFs were created on the left arm. Radiocephalic type of AVF was the most common arteriovenous fistula type found in 111 subjects (66.5\%). The highest postoperative successful rate was found in brachiocephalic type in 78.8\%, followed by radiocephalic AVF type with $66.7 \%$. The wrist region was favorable in subjects (43.1\%).

Conclusions: Arteriovenous fistulas for hemodialysis are needed and in our center. Radiocephalic AVFs are the most common type. Further study to learn the different aspects of arteriovenous fistula cases is needed to fulfill queries in the local population.

Keywords: arteriovenous fistula, end-stage renal disease, hemodialysis access.

Cite This Article: Ledyastatin, R.A., Prasetyo, C.T., Tampubolon, G.S.P., Jiwangga, D. 2021. A three years' experience of Arteriovenous Fistula (AVF) cases in a tertiary care hospital of East Java, Indonesia: a descriptive observational study. Journal of Indonesia Vascular Access 1(2): 24-27. D0I : 10.51559/jinava.v1i2.9

\section{INTRODUCTION}

Based on the latest data shows an estimation of the incidence of end-stage renal disease (ESRD) globally of approximately 700 million persons. ${ }^{1}$ From 1991 until 2007, a study has reported that the proportion of ESRD increased by more than $43 \%$ worldwide. $^{2}$ Hypertension and diabetes mellitus were identified as the prime causes of ESRD in every high-middle-lowincome country globally. ${ }^{2,3}$ Dominantly, patients with ESRD are treated with hemodialysis as renal replacement therapy (RRT) to survive. ${ }^{4}$ Previous studies have reported that hemodialysis remains the primary support in these patients compared to kidney transplantation, especially in developing countries where organ transplantation is infrequently due to lack of donor or other obstacles in the process. ${ }^{5,6}$ Hemodialysis access which can properly function, is a critical need for these patients. Among all hemodialysis access, arteriovenous fistula is considered the most preferred form of vascular access due to the characters with a low risk of infection or complications, the high survival rate of access, and more socially accepted rather than other hemodialysis access. ${ }^{5,7}$

Since recent studies have reported incidence of arteriovenous fistula failure of maturation and thrombosis event, awareness of ensuring the patency and well-functioning of the arteriovenous fistula has become a priority and became the most challenging problem so far. ${ }^{8}$ The study of findings factors that may contribute to its patency and maturation is remains studied. As the tertiary center in East Java Indonesia, Thoracic, Cardiac, and Vascular surgeons in Dr. Soetomo Academic General Hospital have performed the making of an arteriovenous fistula. Since the data from a developing country, such as Indonesia, remain scarce, we aim to present a descriptive characteristic of arteriovenous fistula creation cases in our center with a specific view of demographic parameters, fistulas' sites, type of fistulas. 


\section{METHODS}

We conducted a descriptive study of single-center in the Department of Thoracic, Cardiac and Vascular Surgery of Dr. Soetomo Academic General Hospital Surabaya. We collected the data from January 1st, 2017, to December 31nd, 2020. All patients who undergo arteriovenous fistula creation considered as a subject in this study. We retrieved the characteristics of the type of fistula, the site, surgical technique, and the immediate result of surgery from patients' electronic medical data records.

Our surgeons created all AVF. The AVFs were constructed with end-to-side anastomosis using a 7/0 polypropylene suture. The presence of a palpable thrill over the AVF fistula site and bruit in auscultation after the operation were considered a successful immediate postoperative outcome. We also collected the data of underlying diseases in our subjects like diabetes mellitus and hypertension. The condition called diabetes mellitus requires oral hypoglycemic or insulin therapy or a fasting preoperative blood glucose $>11 \mathrm{mmol} / \mathrm{L}$ (>200mg/ dL). Meanwhile, the definition of hypertension is a systolic blood pressure $>140 \mathrm{mmHg}$, or diastolic blood pressure $>90 \mathrm{mmHg} .{ }^{3}$ We collected the immediate postoperative outcome. The definition of an appropriate outcome is a fistula with positive bruit and thrill in palpation after the anastomosis. Meanwhile, the poor outcome is the fistula with only positive bruit or thrill OR negative bruit and thrill after the anastomosis. We used Microsoft Excel (Microsoft, Inc., Redmond, USA) to operate the data.

\section{RESULT}

Based on three years of our data, 167 AVFs were developed in 167 patients requiring long-term hemodialysis in our center. The characteristics of the subjects are presented in Table 1. Mostly, we found between 5160 years old range in our populations (31.7\%). Females were dominantly in our study with $56.9 \%$. Among 167 AVFs, our surgeons created 159 AVFs on the left arm and only eight subjects on the right arm. Radiocephalic type of AVF was the most common type found in our center
(66.5\%), the wrist region was favorable in subjects (43.1\%). We collected the underlying disease in our patients, which makes the patient need hemodialysis. We found the underlying diseases, including $61.1 \%$ hypertension, $28.1 \%$ in type 2 diabetes mellitus, and $22.1 \%$ in hypertension with type 2 diabetes mellitus. Meanwhile, "others" underlying diseases (10.8\%) showed in Table 1. consist of eight

\section{Table 1. Characteristics Respondent}

\begin{tabular}{|c|c|c|c|}
\hline & Characteristic & $(n=167)$ & $\%$ \\
\hline \multirow{2}{*}{ Gender } & Male & 72 & 43.1 \\
\hline & Female & 95 & 56.9 \\
\hline \multirow{6}{*}{ Age (year) } & $<20$ & 9 & 5.4 \\
\hline & $20-30$ & 6 & 3.6 \\
\hline & $31-40$ & 30 & 18 \\
\hline & $41-50$ & 47 & 28.1 \\
\hline & $51-60$ & 53 & 31.7 \\
\hline & $>60$ & 22 & 13.2 \\
\hline \multirow{2}{*}{ Limb of AVF } & Right & 8 & 4.8 \\
\hline & Left & 159 & 95.2 \\
\hline \multirow{3}{*}{ Types of AVF } & $\mathrm{RC}$ & 111 & 66.5 \\
\hline & $\mathrm{BC}$ & 52 & 31.1 \\
\hline & Brachiobasilic & 4 & 2.4 \\
\hline \multirow{3}{*}{ Place of AVF } & Wrist & 72 & 43.1 \\
\hline & Forearm & 39 & 23.3 \\
\hline & Elbow & 56 & 33.6 \\
\hline \multirow{4}{*}{ Underlying disease } & Hypertension & 102 & 61.1 \\
\hline & Type 2 diabetes mellitus & 47 & 28.1 \\
\hline & Hypertension + Type 2 diabetes mellitus & 37 & 22.1 \\
\hline & Others & 18 & 10.8 \\
\hline
\end{tabular}

$A V F$, arteriovenous fistula; $R C$, radiocephalic; $B C$, brachiocephalic

Table 2. Site of AVF in Hypertension and Diabetes Mellitus Comorbidities

\begin{tabular}{llll}
\hline & & (n) & $\%$ \\
\hline Site of AVF in hypertension & RC & 72 & 70.6 \\
Site of AVF in Type 2 diabetes mellitus & BC & 30 & 29.4 \\
& RC & 32 & 68.1 \\
& BC & 15 & 31.9 \\
\hline
\end{tabular}

$A V F$, arteriovenous fistula; $R C$, radiocephalic; $B C$, brachiocephalic

Table 3. Immediate Postoperative Outcome

\begin{tabular}{clccc} 
& & $\begin{array}{c}\text { Total } \\
(\mathbf{n})\end{array}$ & $\begin{array}{c}\text { Postoperative } \\
(\mathbf{n})\end{array}$ & $\%$ \\
\hline \multicolumn{1}{c}{ Appropriate outcome } & & $\mathbf{1 1 9}$ & $\mathbf{7 1 . 2}$ \\
& Radiocephalic & 111 & 74 & 66.7 \\
& Brachiocephalic & 52 & 41 & 78.8 \\
& Brachiobasilic & 4 & 4 & 100 \\
Poor outcome & & $\mathbf{4 8}$ & $\mathbf{2 8 . 8}$ \\
& Radiocephalic & 111 & 37 & 33.3 \\
& Brachiocephalic & 52 & 11 & 21.2 \\
\hline
\end{tabular}

$R C$, Radiocephalic; $B C$, brachiocephalic subjects with urolithiasis, seven subjects with cervix carcinoma, polycystic kidney in three subjects, lupus erythematosus in two patients, and one patient with kidney hypoplasia. In Table 2. We summarized the type of fistula on the patient with the patients' underlying disease. About 70.6\% were had hyperth radiocephalic fistula type were had hypertension as the underlying disease. 
As shown in Table 3., most fistulae had appropriate outcomes in immediate postoperative outcome (71.2\%), and $28.8 \%$ of subjects had a poor outcome. The highest appropriate outcome was found in brachiobasillic type in $100 \%$ with a total of 4 subjects in this period of study, followed by radiocephalic type in $78.8 \%$. Meanwhile, 37 subjects in radiocephalic fistula type found had poor outcome but only eleven subjects in brachiocephalic type.

\section{DISCUSSION}

Patients with ESRD need vascular access to attain hemodialysis as the prevalent therapy. Among the other three types of vascular access, the preferable access is an arteriovenous fistula. ${ }^{9}$ After the creation of an arteriovenous fistula by surgery. Although, it needs time to obtain arterialization of the vein wall. According to Kidney Disease Outcomes Quality Initiative (KDOQI), the definition of mature in AVF is if the blood flow is $\geq 600 \mathrm{ml} / \mathrm{min}$, vein diameter $\geq 6 \mathrm{~mm}$, $\leq 0.6 \mathrm{~cm}$ depth from the skin, and usually, it takes six weeks after the creation. The definite standard to determine which artery and vein can be used is by using ultrasonography. It can assess the diameter of the artery and vein. Besides the diameter, the location itself must be considered..$^{10}$ From this study, radial artery and cephalic vein on the wrist is the most common widely used for creating AVF in our center. Comparable to the previous research from Italy stated AVF on the wrist was the first definite option due to its low incidence of complication, long term patency rate, and also giving place for a proximal vein that can be used if only the AVF on the wrist (distal) failed to mature. ${ }^{7}$

Proximal access such as Brachiocephalic fistula in the elbow has a higher patency rate than radiocephalic in the wrist or forearm due to the larger diameter of the artery and vein but also has a higher incidence of some complications, such as steal syndrome and high output cardiac failure. ${ }^{7}$ The selection of the limb used to create AVF also must be considered. A cross-sectional study conducted in Japan has suggested that the creation of arteriovenous fistula should be in the non-dominant arm. The intention of this statement is dominant arm is generally used to do day-to-day activities that may harm the maturation of the arteriovenous fistula. Therefore, the non-dominant arm plays a supplementary role or helps the dominant arm do vital work. ${ }^{11}$

Our study also showed the result is persistent with the previous statement, which AVF in the non-dominant arm is likely more found in this study than in the dominant arm. In this study, we found subjects dominantly came with hypertension as underlying disease findings. Although the previous study has stated, there was a benefit value of hypertension in the maturation time and patency of AVFs, however, the mechanism remains unclear. It needs further research with a large population with the proper method. ${ }^{12}$ Diabetes mellitus patient with radiocephalic fistula is more than brachiocephalic nevertheless, the differentiation is not as many as in a patient with AVFs who has hypertension in this study. One of the messages is the increasing risk of AVF failure in diabetes patients, especially in the small diameter of a peripheral artery, so that surgeon usually uses the larger diameter of the vessel to obtain good patency. ${ }^{13}$ Further study to describe the implication of underlying disease such as hypertension and diabetes mellitus in maturation aspects of AVF will help fulfill many queries to proceed with intervention to achieve excellent maturation that may help many patients in the future.

\section{CONCLUSION}

Arteriovenous fistulas for hemodialysis were dominantly in females. Radiocephalic was the most common type of arteriovenous fistula in our center. Hypertension was the underlying disease that causes ESRD in our subjects. Further study to learn the different aspects of arteriovenous fistula cases is needed to fulfill queries in the local population.

\section{CONFLICT OF INTEREST STATEMENT}

All of the authors declare that there were no conflicts of interest in this study.

\section{SOURCE OF FUNDING:}

None

\section{ETHICAL CLEARANCE}

Not applicable

\section{AUTHOR CONTRIBUTION}

All authors contributed equally in the writing of this article

\section{REFERENCES}

1. Heerspink HJL, Stefánsson B V, Correa-Rotter R, Chertow GM, Greene T, Hou F-F, et al. Dapagliflozin in Patients with Chronic Kidney Disease. N Engl J Med. 2020;383(15):1436-46. Available from: http://dx.doi.org/10.1056/ nejmoa2024816

2. Kazemzadeh GH, Modaghegh MHS, Ravari H, Daliri M, Hoseini L, Nateghi M. Primary patency rate of native AV fistula: Long term follow up. Int J Clin Exp Med. 2012;5(2):173-8.

3. Solomonson MD, Johnson ME, Ilstrup D. Risk Factors in Patients Having Surgery to Create an Arteriovenous Fistula. Anesth Analg. 1994;79(4):694???700. Available from: http:// dx.doi.org/10.1213/00000539-19941000000013

4. Vigneau C, Kolko A, Stengel B, Jacquelinet C, Landais $\mathrm{P}$, Rieu $\mathrm{P}$, et al. Ten-years trends in renal replacement therapy for end-stage renal disease in mainland France: Lessons from the French Renal Epidemiology and Information Network (REIN) registry. Néphrologie \& Thérapeutique. 2017;13(4):228-35. Available from: http:// dx.doi.org/10.1016/j.nephro.2016.07.453

5. Pokhrel A, Gyawali P, Pokhrel BR, Khanal MP, Manandhar DN, Bwititi P, et al. Prevalence of Cardiovascular Risk Factors among Chronic Kidney Disease Patients Undergoing Hemodialysis in a Tertiary Care Center, Kathmandu, Nepal. Nepal Med Coll J. 2019;21(4):313-8. Available from: http://dx.doi. org/10.3126/nmcj.v21i4.27629

6. de Castro Rodrigues Ferreira F, Cristelli MP, Paula MI, Proença H, Felipe CR, Tedesco-Silva $\mathrm{H}$, et al. Infectious complications as the leading cause of death after kidney transplantation: analysis of more than 10,000 transplants from a single center. J Nephrol. 2017;30(4):601-6. Available from: http://dx.doi.org/10.1007/ s40620-017-0379-9

7. Santoro D, Benedetto F, Mondello P, Spinelli F, Ricciardi C, Cernaro V, et al. Vascular access for hemodialysis: current perspectives. Int J Nephrol Renovasc Dis. 2014;281. Available from: http://dx.doi.org/10.2147/ijnrd.s46643

8. Konner K, Hulbert-Shearon TE, Roys EC, Port FK. Tailoring the initial vascular access for dialysis patients. Kidney Int. 2002;62(1):32938. Available from: http://dx.doi.org/10.1046/ j.1523-1755.2002.00436.x

9. Bylsma LC, Gage SM, Reichert H, Dahl SLM, Lawson JH. Arteriovenous Fistulae for 
Haemodialysis: A Systematic Review and Meta-analysis of Efficacy and Safety Outcomes. Eur J Vasc Endovasc Surg. 2017;54(4):513-22. Available from: http://dx.doi.org/10.1016/j. ejvs.2017.06.024

10. Chan C, Ochoa CJ, Katz SG. Prognostic Factors for Arteriovenous Fistula Maturation. Ann Vasc Surg. 2018;49:273-6. Available from: http:// dx.doi.org/10.1016/j.avsg.2018.01.069
11. Hara $\mathrm{Y}$, Sonoda $\mathrm{K}$, Hashimoto K, Fuji K, Yamada Y, Kamijo Y. Influence of arteriovenous fistula on daily living behaviors involving the upper limbs in hemodialysis patients: a crosssectional questionnaire study. BMC Nephrol. 2018;19(1). Available from: http://dx.doi. org/10.1186/s12882-018-1097-9

12. Rezapour M, Khavaninzadeh M. Association between non-matured arterio-venus fistula and blood pressure in hemodialysis patients. Med J Islam Repub Iran. 2014;28(1):1-9.

13. Yan Y, Ye D, Yang L, Ye W, Zhan D, Zhang L, et al. A meta-analysis of the association between diabetic patients and AVF failure in dialysis. Ren Fail. 2018;40(1):379-83. Available from: http:// dx.doi.org/10.1080/0886022x.2018.1456464

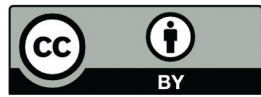

This work is licensed under a Creative Commons Attribution 